Table 1

\begin{tabular}{lccc}
\hline Clinical parameter & Correlated parameters & $\mathbf{r}$ & $\mathbf{p}$-value \\
\hline ESSG diseases activity index & FSFI Arousal domain & -0.300 & $\mathrm{p}<0.0001$ \\
& IIEF EF & -0.597 & $\mathrm{p}=0.0240$ \\
CRP & IIEF Orgasmic Function & -0.668 & $\mathrm{p}=0.0081$ \\
mRSS & MSHQ Sexual Desire & 0.555 & $\mathrm{p}=0.0613$ \\
FIS & BISF-W & -0.410 & $\mathrm{p}=0.0002$ \\
MAF & FSFI & -0.399 & $\mathrm{p}=0.0002$ \\
BDI-II & BISF-W & -0.381 & $\mathrm{p}=0.0002$ \\
HAP & IIEF EF & -0.801 & $\mathrm{p}=0.0005$ \\
& SQoL-F & 0.383 & $\mathrm{p}=0.0006$ \\
& BISF-W & 0.456 & $\mathrm{p}<0.0001$ \\
SHAQ & IIEF EF & 0.639 & $\mathrm{p}=0.0062$ \\
& FSFI & -0.409 & $\mathrm{p}<0.0001$ \\
& BISF-W & -0.451 & $\mathrm{p}=0.0002$
\end{tabular}

Name of Questionnaires/Acronyms: FSFI: Female Sexual Function Index; BISF-W: Brief Index of Sexual Function for Women; SQoL-F/M: Sexual Quality of Life QuestionnaireFemale/Male; PISQ-12: Pelvic Organ Prolapse/Urinary Incontinence Sexual Questionnaire short form; PFIQ7: Pelvic Floor Distress Inventory Questionnaire; IIEF; International Index of Erectile Function; MSHQ: Male Sexual Health Questionnaire; FIS: Fatigue Impact Scale; MAF: Multidimensional Assessment of Fatigue; BDI-II: Beck's Depression Inventory II; HAP: Human Activity Profile; SHAQ: Scleroderma Health Assessment Questionnaire; ESSG: European Scleroderma Study Group; CRP: C-reactive protein; mRSS: modified Rodnan skin score

Results: Compared to HC, women with SSc had significantly higher prevalence and greater severity of sexual dysfunction [FSFI total score (SSc: $16.4 \pm 1.3, \mathrm{HC}$ : $25.6 \pm 1.2, p<0.0001)$ as well as in all subscales $(p<0.0001$ for all), BISF-W total score (SSc: $17.2 \pm 2.3, \mathrm{HC}: 32.0 \pm 1.9, \mathrm{p}<0.0001)$ ], dysfunction of pelvic floor [(PISQ12 (SSc: $3.6 \pm 0.7$, HC: $8.9 \pm 0.6, \mathrm{p}<0.0001$ ), PFIQ7 (SSc: $33.4 \pm 5.6, \mathrm{HC}: 6.8 \pm 1.4$, $\mathrm{p}<0.0001)$ ], and worse sexual quality of life [SQol-F (SSc: $55.3 \pm 3.3, \mathrm{HC}: 82.1 \pm 2.1$, $\mathrm{p}<0.0001)$ ]. Men with SSc also reported more severe sexual dysfunction: [IIEF Erectile function (EF) (SSc: 15.4 $\pm 3.0, \mathrm{HC}: 26.2 \pm 2.1, \mathrm{p}=0.004)$, IIEF - Orgasmic function (SSc: $6.4 \pm 1.2, \mathrm{HC}: 9.0 \pm 0.6, p=0.045$ ), IIEF - Intercourse satisfaction (SSc: 9.7 $\pm 1.8, \mathrm{HC}: 15.7 \pm 1.3, \mathrm{p}=0.008$ ), MSHQ - Erectile Function (SSc: $9.0 \pm 1.2, \mathrm{HC}$ : $12.9 \pm 0.9, p=0.005$ ), MSHQ - Satisfaction (SSc: 19.2 $\pm 2.1, \mathrm{HC}: 26.8 \pm 0.9, \mathrm{p}=0.001$ )] and worse sexual quality of life [SQol-M (SSc: $68.5 \pm 7.4, \mathrm{HC}: 86.7 \pm 6.2, \mathrm{p}=0.023$ )] According to the IIEF classification, $71 \%$ of SSc men reported mild to severe erectile dysfunction. No significant differences were found in pelvic floor function. Significant associations with major clinical parameters are presented in Table 1.

Conclusion: Both women and men with SSc reported significantly impaired sexual function compared to $\mathrm{HC}$ with identical age. Worse scores in SSc were associated with disease activity, increased systemic inflammation, health status, physical activity, fatigue and depression.

Acknowledgments : Supported by MHCR 023728, SVV 260373 and GAUK 1578119.

Disclosure of Interests: Barbora Heřmánková: None declared, Maja Špiritović: None declared, Hana Smucrova: None declared, Sabina Oreska: None declared, Hana Štorkánová: None declared, Kristyna Bubova: None declared, Karel Pavelka Consultant of: Abbvie, MSD, BMS, Egis, Roche, UCB, Medac, Pfizer, Biogen, Speakers bureau: Abbvie, MSD, BMS, Egis, Roche, UCB, Medac, Pfizer, Biogen, Jiří Vencovský: None declared, Ladislav Šenolt: None declared, Radim Bečvář Consultant of: Actelion, Roche, Michal Tomčík: None declared DOI: 10.1136/annrheumdis-2020-eular.3528

\section{SAT0325 STELLATE BLOCKADE COMBINED TO ILOPROST AS SUPPORTIVE TREATMENT OPTION IMPROVES PAIN AND ISCHAEMIC SYMPTOMS IN PATIENTS WITH SYSTEMIC SCLEROSIS}

F. Höcketstaller $^{1,2,3}$, U. Henkemeier ${ }^{1,2,4}$, M. Zimmermann ${ }^{3}$, H. Burkhardt ${ }^{1,2,3,4}$, F. Behrens ${ }^{1,2,3,4}$, U. Drott ${ }^{3}$, M. Köhm ${ }^{1,2,3}$. ${ }^{1}$ Fraunhofer IME Translational Medicine and Pharmacology, Frankfurt, Germany; ${ }^{2}$ Fraunhofer Cluster of Excellence Immune-Mediated Diseases CIMD, Frankfurt, Germany; ${ }^{3}$ Goethe-University Frankfurt, Frankfurt, Germany; ${ }^{4}$ Centre of Innovative Diagnostics and Therapeutics Rheumatology/Immunology CIRI, Frankfurt, Germany

Background: Peripheral ischaemia is a common symptom in systemic sclerosis (SSc) patients with risk of development of digital ulcers (DU). For its treatment, intravenous iloprost is the most effective option. Accompanying pain symptoms worsen the ischaemic symptoms, so a combination with anaesthetic procedures may improve ischaemic status and the subjective sensation of raynaud and pain. The aim of this study was to observe the impact of a combined treatment of iloprost with stellate blockade (ILOST) in improvement of ischaemic symptoms compared to iloprost treatment only (ILO).

Objectives: To evaluate efficacy of the ILOST treatment on changes in vascularisation and sensation of patients with SSc and indication for vasodilatative treatment with lloprost.
Methods: Twenty SSc-patients with indication for ILO-treatment (prophylactic or due to digital ulcerations (DU)) will be included in a prospective observationa study. Patients will be offered to combine ILO with stellate blockade (ILOST). Beside documentation of disease activity characteristics (mRSS, number of DU, capillary microscopy at baseline, after ILO-treatment and at week 12), patients are assessed using fluorescence-optical imaging (FOI) as innovative method for illustration of changes in microvascularisation and patient reported outcomes (DASH, VAS) at week 12

Results: This interims analysis includes the result of the first 11 patients treated. Mean baseline characteristics (age and gender) are well balanced. Iloprost treatment was initiated due to prophylactic treatment to avoid DU in all patients. $100 \%$ of the patients in the ILOST-group were diagnosed as limited SSc compared to $60 \%$ in the ILO-group (diffuse type with $40 \%$ ). All patients showed abnormalities in capillary microscopy (ILOST group: $83,3 \%$ late pattern $16.7 \%$ active pattern; ILO group: $80 \%$ late pattern, $20 \%$ early pattern). MRSS was low in both groups with 1.8 , the disease duration in mean 15.3 years in the ILOST-group compared to 13.2 in the ILO-group, respectively. In both groups, no new DU occurred in the 12-week follow-up. Improvement in VAS pain was reported in $83 \%$ of the patients in the ILOST group compared to $60 \%$ in the ILO group. DASH improved with a mean of 5.5 points in the ILOST group compared to 3 points in the ILO group. FOI was compared individual at both arms in the ILOST group only. The arm with stellatum blockade showed a pronounced increase of $\mathrm{FOI}$ signals of $5 \%$ in mean whereas the opposite site showed a decrease of the signal shortly after ILO treatment indicating a pronounced increase of vascularisation in the ILOST treated body site.

Conclusion: A new treatment approach to improve acute ischaemic symptoms was tested by combining stellate blockade to iloprost treatment. No new DU occurred up to 12 weeks after treatment in all patients of both groups indicating the relevance of iloprost as effective vascular dilatative therapy in SSc. The additional intervention was well tolerated and asked to repeat. Subjective sensation on pain of the hands as well as DASH was improved in the combined group. FOI showed a relevant increase in vascularisation in the blockade arm compared to the opposite site in which signals decreased indicating a stronger effect of the combined treatment for improvement of vascularisation.

Disclosure of Interests: Franziska Höcketstaller Grant/research support from: Rheumazentrum Rhein-Main, Ulf Henkemeier: None declared, Michael Zimmermann: None declared, Harald Burkhardt Grant/research support from: Pfizer, Roche, Abbvie, Consultant of: Sanofi, Pfizer, Roche, Abbvie, Boehringer Ingelheim, UCB, Eli Lilly, Chugai, Bristol Myer Scripps, Janssen, and Novartis, Speakers bureau: Sanofi, Pfizer, Roche, Abbvie, Boehringer Ingelheim, UCB, Eli Lilly, Chugai, Bristol Myer Scripps, Janssen, and Novartis, Frank Behrens Grant/ research support from: Pfizer, Janssen, Chugai, Celgene, Lilly and Roche, Consultant of: Pfizer, AbbVie, Sanofi, Lilly, Novartis, Genzyme, Boehringer, Janssen, MSD, Celgene, Roche and Chugai, Ulrich Drott: None declared, Michaela Köhm Grant/research support from: Pfizer, Janssen, BMS, LEO, Consultant of: BMS, Pfizer, Speakers bureau: Pfizer, BMS, Janssen, Novartis

DOI: 10.1136/annrheumdis-2020-eular.5393

\section{SAT0326 2 SYSTEMIC SCLEROSIS WITHOUT ANTINUCLEAR ANTIBODIES: A MULTI-CENTER STUDY OF EUSTAR COHORT IN CHINA}

M. Hui ${ }^{1}$, J. Zhou2, L. Zhang ${ }^{3}$, X. Duan ${ }^{4}$, M. Li2, Q. Wang2, J. L. Zhao2, Y. Hou2, D. Xu2, X. Zeng2. 'Peking Union Medical College Hospital, Beijing, China; ${ }^{1}$ Peking Union Medical College Hospital, Beijing, China; ${ }^{3}$ ShanXi Bethune Hospital, Xi'an, China; ${ }^{4}$ The Second Affiliated Hospital of Nanchang University, Nanchang, China

Background: The presence of circulating antinuclear antibodies (ANAs) is a hallmark of immune dysregulation and malfunction in patients with systemic sclerosis (SSc) ${ }^{[1]}$. A variety of ANAs ${ }^{[2]}$, including anti-centromere antibody, anti-topoisomerase I antibody, and anti-RNA polymerase III antibody, are associated with unique sets of disease manifestations and widely used in routine clinical practice for diagnosis, clinical subgrouping, risk stratification and prediction of future organ involvements and prognosis in SSc patients ${ }^{[3,4]}$.

Objectives: This study aimed to investigate the clinical features of SSc patients with negative ANAs in a European League Against Rheumatism Scleroderma Trials and Research Group (EUSTAR) and Chinese Rheumatism Data Center (CRDC) multi-center cohort in China.

Methods: Patients were prospectively recruited between April 2008 and June 2019 based on the EUSTAR database and CRDC multi-center cohort from 154 clinical centers nationwide, all of whom fulfilled the 2013 ACR/EULAR classification criteria for systemic sclerosis. Antinuclear antibody testing result was intensively collected. Demographic, clinical, and laboratory data were compared between ANA-positive SSc patients and those with negative ANAs. T-test and chi-square analysis were performed in the comparisons. 